\title{
SUPPRESSING ILLEGAL GUN MARKETS: LESSONS FROM DRUG ENFORCEMENT
}

\author{
Christopher S. KOPER* AND PeTER Reuter**
}

\section{INTRODUCTION}

As the nation contemplates a major effort to reduce the availability of handguns to urban youth, inter alia through aggressive enforcement against illicit transactions, it seems useful to consider what we can learn from the experience of attempting to suppress illicit drug markets.

Since 1985, drug enforcement has probably represented the nation's largest commitment to control an illegal market through criminal sanctions ever undertaken. ${ }^{1}$ Commitments to state prison for drug offenses now constitute about thirty percent of the annual total, or roughly $130,000 .^{2}$ The results are at best mixed. Prices for cocaine, heroin, and marijuana remain very high compared to what they would be in legal markets, at least twenty times the legal price in the case of cocaine. ${ }^{3}$ Perhaps as a consequence, attractive illegal drugs like cocaine are used by many fewer persons than alcohol; how much that should be attributed to illegality per se as opposed to the stringency of enforcement is indeterminable at this time. ${ }^{4}$ On the other hand, these prices have fallen substantially in recent years, ${ }^{5}$ and availability, at least for youths,

Copyright $\odot 1996$ by Law and Contemporary Problems

* Research Scientist, Crime Control Institute, Washington, D.C.

** Professor, School of Public Affairs and Department of Criminology and Criminal Justice, University of Maryland.

This article was initially prepared for The Harry Frank Guggenheim Foundation conference on Disarming Urban Youth, Santa Fe, New Mexico, September 1995. The authors would like to thank Philip Cook, Joseph Sheley, and Lawrence Sherman for helpful comments.

1. Arrests for drug offenses have been about one million since 1992. See U.S. DEP'T OF JUSTICE, CRIME IN THE UNITED STATES, 1993 (1994). The number of felony convictions on drug charges, mostly for trafficking offenses in state courts, has been around 250.000 since 1990. See BUREAU OF JUSTICE STATISTICS, U.S. DEP'T OF JUSTICE, FELONY SENTENCES IN STATE COURTS $(1992,1994)$. In addition, federal courts convict about 20,000 people annually. See BUREAU OF JUSTICE STATISTICS, U.S. DEP'T of JustiCE, Federal CRIMINAL CASE PROCESSING, 1982-83 (1996).

2. BUREAU OF JUSTICE STATISTICS, FELONY SENTENCES IN STATE COURTS, supra note 1 , at 1.

3. Mark H. Moore, Supply Reduction and Drug Law Enforcement, in DRUGS AND CRIME 109, 124 (Michael Tonry \& James Q. Wilson, eds. 1990).

4. Estimates of the price elasticity of demand for illicit drugs suggest that it is quite high (perhaps as much as minus two) for cocaine among those who use that drug frequently. However, the range of observed prices is quite small. See Jonathan P. Caulkins \& Peter Reuter, The Meaning and Utility of Drug Prices, 91 ADDICTION 1261 (1996).

5. On changes in prices, see DRUG ENFORCEMENT ADMIN., THE WHOLESALE AND RETAIL PRICE REPORT (annual). For a careful interpretation, see Jonathan P. Caulkins, What is the Average Price of an llicit Drug?, 89 ADDICrION 815 (1994). 
remains high. ${ }^{6}$ Recent reductions in consumption (both prevalence and quantity) seem to be driven by changes in youth attitudes or by incarceration of users rather than by suppression of the market.

The principal hypothesis of this article is that recent experience with drug markets suggests that enforcement aimed at the market for illicit guns is likely to make only a modest contribution to reducing the availability (as measured by access and price) of guns to urban youth. Generally, the gun market is too informal and too broadly distributed in time and space to allow for effective police penetration. Oddly enough, the opportunity for reduction that does exist may lie at the intersection of the markets for guns and drugs. This observation does not speak to the other major element of control, which is discussed elsewhere in this volume: namely improving the regulation of licit markets so as to reduce the flow of guns into the illicit market from which a large share of the youth guns are obtained.

Comparison of the enforcement against drug and gun markets presents at least two analytic challenges. The first is primarily conceptual: identifying what dimensions of an illegal market influence the effectiveness of enforcement. The second is primarily empirical: determining how drug and gun markets compare on these dimensions. Part II of this article attempts to identify the characteristics of illegal markets that impede effective policing, that is, that make it difficult to raise the price or accessibility of the good or service to the final purchaser. Part III then considers what we know about these characteristics of the illegal markets in which urban youth obtain firearms, particularly handguns. Part IV presents some conclusions about potential strategies for controlling these gun markets.

This article considers only the markets for wholly illicit drugs, principally cocaine, heroin, and marijuana. The more obvious analogy for guns is to the youth market for alcohol. Like guns, alcohol is legally available to adults and the control problem is how to prevent acquisition by youths who are banned from legal purchase. The analogy is particularly close because the law in both cases allows the transfer to youths within families, with parental consent. Moreover, like guns, alcohol is available to youths at quite modest mark-ups compared to the legal price. This itself points to the limited value of analysis of the enforcement of laws against underage purchase of alcohol. Like those against gun acquisition by youths, such efforts have been neither strenuous nor successful, as illustrated not only by the low mark-up but by the large fractions of youths reporting regular binge drinking ${ }^{7}$ and the low salience of the

6. Each year, a national survey of high school seniors asks whether particular drugs are available or readily available; for marijuana, each year $80-90 \%$ of respondents have said that the drug is available or readily available. The percentage reporting similar availability for cocaine rose during the 1980 s from about $30 \%$ to $45 \%$ and only began to drop in the early 1990s. INSTITUTE FOR SOCIAL RESEARCH, MONITORING THE FUTURE (University of Michigan, annual).

7. The percentage of high school seniors reporting that they have drunk five or more drinks at a single session in the previous two weeks has varied between $28 \%$ and $38 \%$ over the last decade. Id. 
enforcement issue until quite recently. The control of the market for drugs that are diverted from licit traffic, such as Valium and other hypnotics, might also be worth examining for insights into gun control. However, the analytic literature on these control efforts is very small.

II

\section{Characterizing Illegal Drug Markets}

Drug markets seem to vary substantially in their vulnerability to the police. In many major cities, heroin is sold in relatively public settings at known times of day, reflecting the rhythms of drug users. ${ }^{8}$ The police are a continuing presence; the number of arrests they make is highly discretionary. If the mayor demands more heroin arrests, the police can certainly provide an increase, probably without much additional commitment; it is the downstream agencies that will be strained. ${ }^{9}$ In contrast, the market for hallucinogens is less defined, with transactions occurring mostly in private settings at unpredictable times; the police are not much of a presence at the retail end.

The critical feature of a market for police purposes is its penetrability, which is interpreted as the cost of creating a level of risk of apprehension for the average transaction. This obviously cannot be measured with much precision because we lack measures either of risk levels ${ }^{10}$ or of enforcement expenditures. ${ }^{11}$ Statements about specific markets commonly represent general observations about what happens as enforcement intensity increases from modest levels. While figures on numbers of arrests for specific drugs are sometimes available, ${ }^{12}$ there are no systematic estimates at the local level of the underlying body of offenses (transactions) so as to permit conversion of arrests into stringency measures. ${ }^{13}$ Cost measures are hard to obtain because much drug enforcement by police is part of their general patrol work. Cost could also be more broadly interpreted to include sacrificed civil liberties; there

8. Some observers report the highest activity rates for such markets are in the morning, between 7:00 and 9:00, suggesting that the first fix of the day is the most urgent.

9. For a fascinating description of that problem in the context of crack in New York City during the mid-1980s, see Aric Press, Piecing Together New York's Criminal Justice System: The Response to Crack, REC. N.Y. BAR ASS'N 541 (1987).

10. Peter Reuter et Al., MONEy from CRIME 35-39 (1990), provides estimates in the late 1980s of the risk of arrest or incarceration per annum faced by a regular seller of drugs (one who sells at least two days per week) in street markets in Washington, D.C. We know of no other estimates, and the Reuter figures are rough at best.

11. Aggregate measures of drug enforcement expenditures by state and local agencies have been published for 1990 and 1991. OFFICE OF NAT'L DRUG CONTROL POL'Y, STATE AND LOCAL SPENDING ON DRUG CONTROL ACTIVITIES (1993). At the individual city level, we know of no systematic estimates.

12. A central problem in getting drug-specific arrest figures is that the FBI retains a very traditional classification system for drugs in its Uniform Crime Reports system. Cocaine and heroin arrests are in one category, and many police departments do not provide more detailed information.

13. For a discussion of this measurement issue, see Peter Reuter, On the Consequences of Toughness, in SEARCHING FOR ALTERNATIVES: DRUG CONTROL POLICY IN THE UNITED STATES 138 (Edwin Lazear \& Melvin Krauss eds., 1990). 
are extremely intrusive measures (for example, random testing of citizens for the presence of drugs in their bodies) that might not be resource intensive but would be regarded as very costly in a democratic society.

Without providing an exhaustive list, we suggest that the relevant variables for market penetrability in this context can be clustered into three broad categories: consumer characteristics (spatial density, poverty, criminality ${ }^{14}$ ); consumer-product interactions (frequency of transactions by individual customers, urgency/impulsiveness of purchase); and distribution-product interactions (length of distribution chain, bulkiness of item, and ease of entering the market as a supplier).

Note four aspects of this list. First, not all items are independently determined. For example, the poverty of users will increase the frequency of purchase, because impoverished users will have more difficulty accumulating funds for large purchases. The density of customers also facilitates more frequent transactions by reducing search time per purchase. Second, interactions may be at least as important as the main effects. For example, impulsivity increases vulnerability to enforcement, particularly when transactions need to be frequent; if a drug is purchased on a quarterly basis, even an impulsive purchase exposes the buyer to enforcement only occasionally. Third, the analysis is complicated by the fact that most, if not all, the variables are enforcement sensitive. For example, enforcement affects the bulkiness of the item directly (use of more potent forms of a drug ${ }^{15}$ ) and indirectly (high prices may induce smaller unit purchases ${ }^{16}$ ), as well as affecting who chooses to purchase. Data to separate the inherent characteristics are not available, allowing a free field for judgment. Finally, note the lack of reference to the psychoactive effects of the drug; though much tends to be made of differences in violence between the heroin and cocaine markets, the markets for other stimulants with similar psychoactive properties is also very different from that for cocaine.

The development of specific market "places" is critical for drug enforcement. Indeed, police and many analysts tend to think of drug markets as locations rather than abstract arrangements of buyers and sellers. Locational specificity arises in many retail drug markets from the desire of buyers and sellers to find each other efficiently. However, this also allows police to deploy their patrol resources more efficiently. One can observe the same phenomenon in illegal gambling. Telephone wagering greatly reduced the enforcement vulnerability of bookmakers, who used to run storefront walk-in operations, precisely because

14. This refers to crimes other than participation in the specific illegal market.

15. More potent forms of drugs are more readily concealed. Indeed, a common charge against prohibition regimes is that they encourage the consumption of more potent and dangerous forms of substances. See generally, MARK THORNTON, THE ECONOMICS OF PROHIBITION (1991).

16. This effect refers not to the form of the drug but the size of the average transaction. 
there was no longer a specific location at which bettors had to congregate. ${ }^{17}$ Similarly, individual high-level drug transactions reduce transaction vulnerability by having the buyer and seller fix a location specific to each transaction. ${ }^{18}$ Much of the analysis that follows is about the factors leading to markets being concentrated in space and time.

\section{A. Customer Characteristics}

1. Density and Separation of Buyers and Sellers. Where buyers and sellers come from the same community, markets may be able to move without loss of efficiency because information about location is readily communicated among participants on a short-term basis. Peter Reuter and Robert MacCoun argue that this ability to relocate leads to geographic markets (labeled "local") that are relatively robust to police interventions. ${ }^{19}$ Heroin and crack markets tend to have this characteristic, since most buyers are sometimes sellers and vice versa. If forced from a current location by police activities, they will tend to find each other again. In contrast, cocaine and LSD markets frequently show more separation of buyers and sellers; the latter come from the dealing neighborhood and the buyers from other areas where open markets are harder to find. Consequently, these markets are more susceptible to breaking up under police pressure. For yet other drugs, such as hallucinogens and marijuana, the market is not a place but simply notional; enforcement consequently lacks focus.

2. Criminality. While Jerome Skolnick's classic observation of the 1960s-that the drug squad ignores its targets' burglaries while the burglary squad ignores its targets' drug purchase ${ }^{20}$ — still has some relevance, our impression is that police and prosecutors are now likely to permit a felonious drug user to obtain some relief on other arrests by providing information about his supplier. This represents the increased prominence of illicit drugs as a social problem. A heroin dealer is at risk from the fact that his clients are frequently arrested for other crimes; ${ }^{21}$ a marijuana dealer is on average at lower risk of

17. On how this change affected the organization of bookmaking and associated corruption, see PETER ReUter, Disorganized CRIME 45 (1983). Customers may have regretted the loss of social ambiance that went with such congregation (well described, albeit in faux form, in the film THE STING (MCA Home Video 1985)).

18. Transaction vulnerability may nonetheless be higher for wholesale than for retail transactions because the police invest more resources in pursuing high-level dealers and will trade charges against a retailer for information that will allow interception of such a transaction.

19. Peter H. Reuter \& Robert J. MacCoun, Street Drug Markets in Inner-City Neighborhoods: Matching Policy to Reality, in URBAN AMERICA 227 (James Steinberg et al. eds., 1992).

20. Jerome H. Skolnick, JUSTICE WrrHOUT TRIAL (3d. ed. 1994).

21. Data from the Drug Use Forecasting program suggest that a substantial fraction of the estimated 500,000 to 1 million heroin addicts are arrested each year, mostly for non-drug crimes. For example, $18 \%$ of all male, booked arrestees in New York County (Manhattan) tested positive for opiates (predominantly heroin) in 1992; in Chicago the percentage was $19 \%$. Urinalysis figures appear in NAT'L INST. OF JUSTICE, U.S. DEP'T OF JUSTICE, DRUG USE FORECASTING (1993); the estimate of the number of heroin addicts comes from WILLIAM RHODES ET AL., OFFICE OF NAT'L DRUG 
having a regular customer turn into an informant. Customer criminality may also increase dealer preference for public settings for transactions. Addicted and violent customers make private places dangerous settings; such customers may be as much a source of risk as the police. ${ }^{22}$ Non-addicted and wealthier users may also be reluctant to transact in private settings with sellers who are frequently poor and addicted. Public settings increase exposure to police intervention.

3. Poverty. Wealthy cocaine users, at least early in their cocaine careers, are more likely to purchase in private settings. In contrast, the poor pay less than wealthy purchasers but compensate for that by taking greater risks in their purchase. The poor are unable to purchase large bundles and value their own time and risks less than wealthier users; sellers are less willing to travel to the customer for small quantities and the user is more willing to come to the seller, even in a public setting. The hallucinogen market generally has wealthier users who seem to avoid public locations. ${ }^{23}$

\section{B. Consumer-Product Interactions}

1. Frequency of Transaction. Sale transactions provide the most vulnerable moment in a market. Certainly most drug arrests occur as the consequence of an observed or simulated sale; consumption or simple possession rarely produces arrests. ${ }^{24}$ Infrequent transactions reduce opportunities for police to intervene effectively. One reason that enforcement against higher levels of drug markets is expensive (per arrest if not per gram ${ }^{25}$ ) is that transactions occur only on a weekly or monthly basis. ${ }^{26}$ Similarly, marijuana retail markets are probably

CONTROL POL'Y, What AMERICA'S USERS SPEND ON ILlEGal DRUGS, 1988-1993, at 12 (1995).

22. No data directly address the extent of customer violence against dealers. The only study of the sources of drug-related homicides found that most were accounted for by systemic factors, rather than psychopharmacological effects or economic compulsive effects. Paul J. Goldstein et al., Crack and Homicide in New York City, 1988: A Conceptually-Based Event Analysis, 16 CONTEMP. DRUG PROB. 651. 684 (1989).

23. On the relationship between income and use of specific drugs, see DEP'T OF HEALTH AND HuMAN SERV., NAT'L HOUSEHOLD SURVEY ON DRUG ABUSE: MAIN FINDINGS, 1993 (1995).

24. These statements are speculations but not, we believe, controversial ones. A substantial fraction of possession arrests are not transaction-related, e.g., an officer observes paraphernalia in the course of a vehicle stop. However, sales arrests are a rising share of all drug arrests and account for most imprisonments.

25. High-level dealers earn large incomes per transaction, presumably for incurring higher total risks both from enforcement and from other market participants. However, compensation per gram is much lower than at retail, since the risk is distributed over many grams. A retailer typically marks up his purchase price by about $75 \%$, amounting to perhaps $\$ 60$ per gram; he earns only $\$ 30$ per transaction. A multi-kilo dealer, buying 25 kilos at $\$ 20,000$ per kilogram and selling in five kilogram units at $\$ 25,000$ per kilo, adds only $\$ 5$ per gram but earns $\$ 25,000$ per transaction. See generally PETER REUTER \& JoHn HAAGA, THE ORganization OF HIGH-LEVEL DRUG MARKETS: AN EXPLORATORY STUDY (1988).

26. However, larger bundles may be more vulnerable during storage. The largest cocaine seizure occurred when 20 tons was discovered in a warehouse outside Los Angeles. Seth Mydans, Agents Seize 20 Tons of Cocaine in Raid on Los Angeles Warehouse, N.Y. TIMES, Sept. 30, 1989, at A1. 
less vulnerable to enforcement (as measured by either the absolute or percentage mark-up at the retail level) because purchases are typically made on a weekly or less frequent basis, compared to a daily basis for cocaine and heroin..$^{27}$

The frequency of drug dealers' transactions is quite remarkable, given that each one is illegal. Peter Reuter, Robert J. MacCoun, and Patrick Murphy estimate that a regular drug dealer, one who sells more than one day per week, is likely to make at least 1,500 transactions each year. ${ }^{28}$ To give a more global sense of the volume of drug transactions, the estimated 300 tons of cocaine consumed annually alone generates 300 million one-gram sales each year; all drug retail transactions might total over one billion. ${ }^{29}$

2. Urgency and Impulsivity of Purchase. Drug users frequently wish to obtain their drugs immediately; indeed, one of the defining characteristics of addiction is the urgency, such that the drive for the drug may dominate the individual's behavior. ${ }^{30}$ This leads to less caution in search behavior. The timing of the need may not be readily predictable (impulsivity), increasing the importance of having immediately accessible sources. Street drug markets are like convenience stores; they are always open. The turnover and unreliability of dealers will promote dense and locationally specific markets. ${ }^{31}$

\section{Distribution-Product Interactions}

1. Length of Distribution Chain. Heroin and cocaine enter the country in large bundles. For example, 500 kilograms of cocaine, a typical interdiction seizure, represents about 500,000 retail purchases. Hence, there are numerous high- and intermediate-level transactions, ${ }^{32}$ and, at least for small or immature

27. Frequent purchases by cocaine users may represent both efforts at self control (not having to abstain when in possession of the drug, thus spreading out the total pleasure for a given expenditure) and the difficulty of accumulating the money required for larger purchases. See MARK A. R. KLEIMAN, AGAINST EXCESS: DRUG POLICY FOR RESULTS 114 (1992).

28. PETER REUTER ET AL., MONEY FROM CRIME 60 (1990).

29. For total consumption estimates, see RHODES ET AL., supra note 21 , at 19 . Cocaine is not always sold in one gram units. Crack is typically sold in units containing only about 50 milligrams of pure cocaine, while some powder users purchase in quarter-ounce (seven gram) bundles. The figure for transactions is certainly in the order of hundreds of millions. For heroin, a similar calculation can be performed; typical purchases are of 25 milligrams of pure heroin, so that the roughly 10 tons consumed would generate about 400 million transactions.

30. Am. PSYCHIATRIC ASS'N, Diagnostic AND StatistiCAl MANUAL III, at 166 (1987).

31. Not all impulsive purchases are urgent, nor are all urgent purchases impulsive, but many transactions are both. A heroin addict knows that his need for the drug is high early in the morning (urgency) and thus may be able to prepare for it (non-impulsive). An occasional cocaine user may make an impulsive purchase as the result of a specific external cue or personal encounter.

32. The number is small when compared to the total of retail transactions; however, each gram is exposed in a number of transactions, only one of which is the final retail sale. Assume that each highlevel seller is willing to deal with five customers, to keep risk acceptable; then, the total number of nonretail transactions for the 500 kilograms is about 95,000 . compared with the 500,000 retail sale transactions. 
markets, success in incapacitating high-level dealers potentially reduces the efficiency of the market. ${ }^{33}$ Marijuana, because of the extent of small-scale domestic production, is less vulnerable to localized interruptions.

2. Bulkiness. Drug purchases are essentially invisible (except perhaps to the highly trained eye $^{34}$ ) because the quantity of drug involved is so slight, typically one gram or less, including dilutents. Alcohol prohibition presented different opportunities for enforcement (and corruption) simply because a retailer had to stock such large quantities (including a variety of drinks) that they could not be readily concealed.

3. Entry. In theory, manipulation of barriers to entry is a strategy for enforcement agencies. One rationale, though not the only one, ${ }^{35}$ for focusing enforcement efforts on high-level drug dealers is that there are entry barriers to that level of the market, so that it will be difficult for newcomers to replace those who are incarcerated. As a result, the remaining suppliers will have the capacity to control the market and raise prices, and/or supplies will actually be interrupted.

Indeed, some illegal markets require suppliers to have specialized resources (for example, in the nuclear weapons market, access to stockpiles of weaponsgrade plutonium) or large quantities of capital. ${ }^{36}$ Specific skills are rarely necessary for the entrepreneur because those skills may be purchased from agents, that is, pilots with licenses and the capability to handle certain types of aircraft, or technicians capable of producing LSD. We are unable to identify drug-dealing skills that are held by only small numbers of persons or that require much education. Drug dealing, at least within the United States as opposed to international smuggling, requires no skills or specialized resources. The capital required for entry into the higher levels may be substantial, a 500kilogram shipment representing a value of about ten million dollars, but revolving credit is often available to those who have shown themselves reliable in lower level transactions; experience can be a substitute for capital.

In summary, enforcement should be able to do more to raise price and reduce access in drug markets characterized by (in order of probable impor-

33. The statements about the impact of high-level transactions on the efficiency of markets are purely speculative. Only in the case of the crackdown on the Medellin cartel in 1990, which led to a sharp one-year increase in cocaine prices, is there any evidence of such an effect. See WILLIAM RHOdEs ET AL., OFFICE OF NAT'L DRUG CONTROL POL'Y, PRICE AND PURITY OF COCAINE: THE RELATIONSHIP TO EMERGENCY ROOM VISITS AND DEATHS AND TO DRUG USE AMONG ARRESTEES (1992).

34. Researchers who have ridden with police are frequently impressed by how well experienced officers interpret body movements to reveal drug transactions.

35. Other rationales include: (1) those who profit most from an illegal market should face the highest risk of being punished, and (2) those who serve as role models for entrants into the business because of their financial success should be seen to be the subject of punishment.

36. We assume here that capital markets for illicit enterprises are imperfect because of impediments to the flow of information and high contract enforcement costs. 
tance) frequent transactions, urgent and/or impulsive purchases, poor and criminally active users, bulky products, and lengthy distribution chains. The first three of these are the characteristics that are likely to generate specific and public marketplace locations. We now turn to a consideration of the characteristics of gun markets, using this hierarchy to organize our inquiry.

\section{III}

\section{GUN MARKETS}

Because the concern with juvenile use of guns has only recently become prominent, the scholarly literature on patterns of acquisition, essential to understanding the role of illegal gun markets, is very modest. We make abundant use of journalistic materials to flesh out our description of how juveniles acquire guns.

\section{A. Frequency of Transactions}

Specific data with which to estimate the frequency of illegal gun transactions by individuals (either as buyers or sellers) are very scanty, primarily anecdotal, and focused on sellers rather than purchasers. At the extreme, one can find stories of unscrupulous federal firearm licensees selling hundreds or perhaps thousands of guns knowingly over multiple-month periods to felons, drug dealers, and/or gangs. ${ }^{37}$ Generally though, persons engaged in illegal gun sales appear to make quite modest numbers of transactions. In a number of journalistic accounts, the business of gun runners ranged from ten to fifteen sales a week ${ }^{38}$ to an estimated two or three a month. ${ }^{39}$ For example, one Washington, D.C., teenager involved in gun dealing reportedly used straw purchasers to obtain sixty-one semiautomatic firearms from Virginia stores over a five-month period, which he then sold to persons in Washington, D.C. Assuming that these were the only guns he sold during that time (perhaps a tenuous assumption), this amounted to twelve sales per month, or three per week. In another example thought by federal officials to be typical of the size of most gun running operations, a New York trio procured and sold 116 weapons over a four-month period. ${ }^{40}$ This amounts to approximately twentynine sales a month or seven per week. ${ }^{41}$

37. Matt O'Connor, 6 Years for Illegal Gun Sales, CHI. TRIB., July 19, 1995, \& 2, at 3; Pierre Thomas, DC's Modern-Day Gun Runners, WASH. POST, Aug. 18, 1991, at A1.

38. Pete Earley, The Gun Dealer, WASH. POST, Mar. 8, 1981, at A1.

39. Rene Sanchez, Building an Arsenal, One Gun at a Time, WASH. POST, Nov. 3, 1993, at A1; Pierre Thomas, Virginia's Deadly Export, WASH. POST, Feb. 2, 1993, at A1; Mark Moore, Enforcement Strategies to Keep Guns from Offenders and Off City Streets (1983) (unpublished manuscript, Kennedy School of Government, Harvard University).

40. Thomas, supra note 37, at A1.

41. If these transactions were spread out among the three people, it would have lowered the number of transactions conducted by each member of the group. 
Of course, these are strikingly low figures compared to the figures on sales by drug retailers cited above, on the order of thirteen per day on days of selling. ${ }^{42}$ A dealer who operated three days a week, typical of those in the Reuter, MacCoun, and Murphy sample, would make about 150 sales per month.

Data regarding the frequency of gun purchases by buyers are virtually nonexistent. However, we might use data from James Wright and Peter Rossi's survey of serious adult felons to develop a rough approximation. On average, these respondents had owned a total of six handguns during their lives. ${ }^{43}$ The mean age of the respondents was twenty-eight, and the mean age at which they first acquired a handgun was eighteen. Wright and Rossi also reported that the average respondent had spent five years in prison at the time of the survey. ${ }^{44}$ If we adjust for time spent in prison, it appears that these rather serious adult offenders had acquired handguns at a rate of only about one per year. Thus, it appears that even serious felons make gun purchases rather infrequently. However, these figures may have limited use in generalizing about youths and the current time period; the increasing pressure to always carry a gun may increase the frequency of gun purchases.

It is not difficult to enumerate factors likely to reduce the frequency of gun purchases by individual users as compared to drug purchases. One is the sheer durability of guns. A specific gun may become unattractive because it has been used in a particular crime and thus becomes incriminating to the owner. However, a gun is clearly a durable good, in sharp contrast to the extreme perishability of drugs in the hands of addicted users. Much of the utility of a gun comes from possession per se, not its use, again encouraging longer ownership.

Another factor is the price of guns. Gun prices vary substantially in different journalistic and scholarly accounts of gun buying. These variations in price depend on many variables, such as the quality of the weapon and whether the firearm is new or used. The level of gun control in the jurisdiction would seem to play a role as well; more stringent control can raise the price in illicit transactions. ${ }^{45}$ Also influential is the situation or motivation of the seller; in some cases, drug addicts in need of their next fix may sell firearms for as little as ten dollars. ${ }^{46}$ Yet quality firearms often cost hundreds of dollars even in illegal transactions, thus preventing most youths from making frequent purchases. ${ }^{47}$

42. Selling is typically carried out only about four hours on any day. PETER REUTER ET AL., MONEY FROM CRIME 61 (1990).

43. James D. Wright \& Peter H. Rossi, ARMed and Considered Dangerous: A SURVey OF FELONS AND THEIR FIREARMS 80 (2d. ed. 1994).

44. Id. at 45 .

45. Philip J. Cook et al., Regulating Gun Markets, 86 J. CRIM. L. \& CRIMINOLOGY 59, 71 (1995).

46. Bill Walsh, Drugs Feed Gun Markets, N.O. TIMES-PICAYUNE, July 25, 1993, at A14.

47. Cook et al., supra note 45 , at 71 . 
Further, ethnographic research ${ }^{48}$ and media accounts ${ }^{49}$ suggest that youths often share guns in order to reduce the risk of getting caught with an illegal firearm and, presumably, to lower each youth's cost for the weapon. Indeed, fifteen percent of Seattle youths who own a handgun appear to share ownership of the gun with one or more friends. ${ }^{50}$ Similarly, the existence of various loaning and sharing arrangements is suggested by Sheley and Wright's discovery that gun carrying is more prevalent than gun ownership among inner-city students. ${ }^{51}$ On the other hand, some youths who do not purchase guns may rent them, and this could conceivably increase the number of transactions they make. Besides sharing arrangements, one or more youths in a group might purchase weapons on behalf of the other youths, ${ }^{52}$ thereby lowering the necessary number of market transactions. Drug dealers are often known to equip their subordinates in this manner. ${ }^{53}$

To make the point about frequency more forcefully, we offer an aggregate estimate of the annual number of street purchases by adolescent males in the District of Columbia in the Appendix; the estimate takes no account of factors peculiar to Washington's gun control regime. Using fairly generous assumptions, likely, if anything, to bias the figure upwards, we estimate that the annual purchase figure is about 2,200 , or about six guns per day. If we include eighteen- to twenty-year-olds, who are not permitted to purchase handguns from federal firearms licensees, the figure rises to thirteen per day. This last figure is about the volume of sales of one drug dealer in the course of a single afternoon, and there are literally thousands of such drug sellers. The number of gun sales appears to be three orders of magnitude smaller than the number of drug sales.

\section{B. Urgency and Impulsivity of Purchase}

Among both juvenile inmates and students, protection is the most important reason for gun ownership. ${ }^{54}$ The perceived need for protective gun ownership is understandable; forty-five percent of the students surveyed by Sheley and Wright reported that they had been "threatened with a gun or shot at on the

48. David M. Kennedy et al., Youth Violence in Boston: Gun Markets, Serious Youth Offenders, and a Use-Reduction Strategy, 59 LAW \& CONTEMP. PROBS. 147 (Winter 1996).

49. Walsh, supra note 46 , at A14.

50. Charles M. Callahan \& Frederick P. Rivara, Urban High School Youth and Handguns: A School Based Survey, 267 JAMA 3038, 3039 (1992).

51. JOSEPH F. SHELEy \& JAMES D. WRIGHT, NAT'L INST. OF JUSTICE, GUN ACQUISITION AND POSSESSION IN SELECTED JUVENILE SAMPLES 5 (1993). However, this pattern is not common to all available survey data. See Callahan \& Rivara, supra note 50, at 3039-40. Sharing, loaning, or renting arrangements are also a potential factor in investigations linking the same firearm to multiple murder incidents.

52. Robert Hanley, 6 Teenage Friends Are Arrested in Conspiracy to Buy Illegal Guns, N.Y. TIMES, Mar. 16, 1995, at B5.

53. Cook et al., supra note 45 , at $64-65$.

54. SHELEY \& WRIGHT, supra note 51 , at 7-8. 
way to or from school in the previous few years." ${ }^{" 55}$ Nevertheless, it is not clear how often youths seeking guns are in some sort of imminent danger that creates an urgent need to procure a gun quickly. In a study of junior high school students in Washington, D.C., having been threatened or attacked with a gun was not significantly related to having carried a gun for protection, though gun carriers did tend to know more persons victimized by violence. ${ }^{56}$ This suggests that to the extent gun carrying is defensive, it is most often a response to general environmental conditions rather than personal victimization. However, this generalization may not apply as strongly to older adolescents; Sheley and Wright did find evidence that gun-related victimization (that is, having been threatened with a gun or having been shot at while in school or while traveling to and from school) is associated with gun carrying among inner-city high school students. ${ }^{57}$ Even so, it is still unclear how often juveniles acquire guns because they perceive an urgent need.

Urgency may be a factor for gun sellers more often than for buyers. In particular, drug addicts with weapons to sell sometimes face an urgent need to sell their wares for drugs or cash when in need of their next fix. As mentioned previously, crack addicts in some cities may sell guns for as little as ten dollars in order to get quick money for crack. ${ }^{58}$ One New Orleans youth owning a .45 caliber handgun described the situation, "Sometimes the guns just come to you .... I had a dude come up to me and ask me, 'Do you want to buy a gun?' I said 'Yeah' and I gave him a dime (\$10) rock [of crack]."'59 Seller urgency also has implications for the spatial dimensions of gun markets, for it suggests that juveniles can get guns quickly by visiting locations known for drug transactions.

On the other hand, other anecdotal evidence suggests that gun transactions can take a few days to set up even when the buyer has an urgent need for a gun. For example, a Washington, D.C., youth who had lost his gun remained indoors for more than two weeks until he was able to acquire a new gun. ${ }^{60}$ The search time generally required to obtain a gun indicates that many juvenile gun buyers are not aware of specific locations where they can get guns quickly. ${ }^{61}$

55. Id. at 4 .

56. Daniel W. Webster et al., Weapon Carrying Among Inner-City Junior High School Students: Defensive Behavior vs. Aggressive Delinquency, 83 AM. J. PUB. HEALTH, 1604, 1606-07 (1993).

57. Joseph F. Sheley et al., Gun-Related Violence in and Around Inner-City Schools, 146 AM. J. DISEASES CHILDREN 677, 679 (1992).

58. Walsh, supra note 46 , at A14.

59. Id.

60. Nancy Lewis, Court Cases Reveal Arms Buildup Among D.C. Youths, WASH. POST, Jan. 1, 1995, at A1, A24.

61. One observer has also speculated that offenders having their guns seized by police may experience difficulties or delays in obtaining new guns and that this may have been partially responsible for the results of a recent study in Kansas City showing that increasing gun seizures within a high gun crime target area significantly reduced gun crime in that area. LAWRENCE W. SHERMAN, REDUCING Gun Violence: COMMUNity POlicing AgAinst GuN CRIME (Nat'l Inst. of Justice, Research in Progress Videotape Series 1995). 


\section{Density and Separation of Buyers and Sellers}

Many youths can obtain firearms from family or friends, thus eliminating their need to seek out formal markets. Gun ownership and gun carrying appear to be common among the friends and relatives of many urban youths. Survey evidence suggests that thirty-nine percent of inner-city students have one or more male family members who carry guns regularly and thirty-five percent have one or more friends who carry guns regularly. ${ }^{62}$ In Sheley and Wright's survey of juvenile inmates and inner-city students, eighty-one percent of the inmates and eighty-eight percent of the students indicated that they could buy or borrow guns from relatives or friends. ${ }^{63}$ Perhaps more telling, among respondents who owned handguns, thirty-six percent of the inmates and sixtyone percent of the students named a friend or family member as the source of their most recent handgun acquisition. ${ }^{64}$ The percentages citing "the street," a "drug dealer," or a "drug addict" as their source were forty-three percent for inmates and twenty-two percent for students. ${ }^{65}$ Thus, friends and family appear to be more important than street sources for youths in general, though perhaps not for the most seriously delinquent youths.

Furthermore, among the thirty-two percent of juvenile inmates and eighteen percent of students who had previously asked someone to purchase a gun for them at a gun shop, pawn shop, or other retail outlet, the majority had asked friends or relatives to make the purchases. ${ }^{66}$ Only seven percent of these inmates and six percent of these students had asked strangers to make the purchases. ${ }^{67}$ Thus, youths reduce their exposure to intervention by enforcement agencies by keeping to a circle of intimates in their weapons acquisition efforts.

Charles Callahan and Frederick Rivara have reported similar results from their survey of public high school students in Seattle. ${ }^{68}$ Among students who perceived handguns to be easily accessible, about fifty-nine percent indicated they would obtain a handgun from friends or their homes, while twenty-eight percent cited street sources as their most likely alternative. ${ }^{69}$ Among thirtyone respondents owning only handguns, twenty-nine percent had received their handguns as gifts (virtually all of which were from parents) and twenty-two

62. Sheley et al., supra note 57 , at $680-81$.

63. SHELEY \& WRIGHT, supra note 51, at 6.

64. $I d$.

65. Another $14 \%$ of the inmates and $6 \%$ of the students cited theft or "other" as their source. Id. For comparative purposes, it is interesting to note that in Wright and Rossi's study of serious adult felons, $44 \%$ of the handgun owners had obtained their most recent handgun from friends or family, while $26 \%$ cited street sources such as fences, drug dealers, or the "black market" as the source of their most recent handgun. WRIGHT \& Rossi, supra note 43, at 183.

66. SHELEY \& WRIGHT, supra note 51, at 6-7.

67. Id.

68. Callahan \& Rivara, supra note 50 , at 3039

69. This calculation removes those respondents who already owned a handgun and those who indicated that they would not need one. Id. 
percent had received their guns from friends. ${ }^{70}$ Nineteen percent had gotten their guns from street sources. ${ }^{71}$ Again, family and friends were more important than street transactions.

Hence, it appears that many youthful gun buyers and sellers are linked to one another through social networks. To a significant degree, the participants are dealing with others whom they know. Sheley and Wright's inmate respondents, for instance, indicated that when they traded or sold guns they had stolen, "they generally did so to friends or other trusted persons."72 Media accounts also suggest that youths who desire guns can often ask around among their friends or schoolmates and obtain a gun within a few days. ${ }^{73}$ This familiarity among buyers and sellers decreases the need for gun markets in public locations in at least two ways. First, both parties can easily arrange for transactions to take place at a specified location and time. Second, sellers are less likely to feel threatened by customers with whom they have other ties.

The fact that guns are durable goods and at any one time are held by many individuals is another factor reducing the need for anonymous transactions, as compared to drug markets. At any given moment, an urban adolescent will have a number of friends or relatives who are potential sources of a gun, whether for hire or purchase. Though drugs are used by many people in the same communities, their willingness to sell or share at a given moment is much lower, given the small and ephemeral character of inventory. We suspect that this is a major factor in explaining why our estimate for the number of street transactions involving guns for youths in Washington, D.C. is so low.

A dealer's knowledge about who is a reliable customer is a major tool for enforcement agencies attempting to control drug markets. ${ }^{74}$ Potential sellers may be deterred if they are unable to discriminate confidently between genuine buyers and informants. At the retail level, the heroin seller who is himself an experienced user (as the vast majority are) is likely to know enough users intimately that risks would be modest except that users are at high risk of becoming informants for relief of their own enforcement problems. A prudent and unambitious retailer of guns may never need to deal with a stranger, so turning customers into informants may be the only way for enforcement agencies to increase a dealer's risk. However, it is not clear whether youthful gun buyers are frequently arrested or whether the juvenile justice system routinely engages in plea bargaining in return for information. Moreover, the vulnerability of gun sellers in this respect is a function of the number of customers they have and the probability that a customer will be charged with

70. Id. at 3040 .

71. Id.

72. SHELEY \& WRIGHT, supra note 51 , at 6.

73. James Rowley, Guns Easy for City Kids to Come By, Study Says, SAN Diego UnION TRIB., Dec. 16, 1993, at A29.

74. This is the central insight of the classic article by Mark Moore on strategies for drug enforcement. Mark H. Moore, Policies to Achieve Discrimination on the Effective Price of Heroin, 63 AM. ECON. REV. 270 (1973). 
a criminal offense and given the opportunity to reduce the severity of charges by providing information. Because most sellers have very few customers, the risks that can be imposed by this means are modest.

The 1994 federal crime bill now prohibits private transfers of handguns to juveniles, except with prior parental notification. ${ }^{75}$ Perhaps this will have some deterrent effect, making it more difficult for youth to obtain handguns in the future.

\section{Length of Distribution Chain}

Because the production, importation, and sale of guns are legal (in most cases), gun markets do not require the lengthy distribution chains associated with most illicit drugs. It appears that most guns obtained by youth come from small localized distribution efforts; there are no equivalents to the high-level drug distributors.

Despite the prohibition on retail gun sales to juveniles, a modest percentage of juveniles feel that they can obtain guns directly from retail outlets. Among Sheley and Wright's respondents, twelve percent of the juvenile inmates and twenty-eight percent of the students named gun shops as likely sources from which they could obtain firearms; another eight percent of the inmates and four percent of the students cited theft from a store or pawnshop as an alternative. ${ }^{76}$ Similarly, it appears that between twelve and thirteen percent of Seattle teens who perceive access to handguns to be easy would procure guns from gun shops. ${ }^{77}$ Consistent with this, only small to modest percentages of gun-owning juveniles appear to have actually procured their weapons from retail outlets. Among handgun owners in the Sheley and Wright sample, seven percent of the inmates and eleven percent of the students indicated that they had obtained their most recent handgun from a gun shop or pawn shop. ${ }^{78}$ Among thirty-one Seattle high school students having sole ownership of one or more handguns, about six percent (just two respondents) had acquired their guns from a gun store. $^{79}$

Federal firearm licensees ("FFLs") who are willing to violate various laws can provide an easy and direct source of guns for many juveniles and adults otherwise prohibited from making legal gun purchases. Recent evidence indicates that more than half of the weapons submitted by police to the U.S. Bureau of Alcohol, Tobacco, and Firearms for tracing originate with less than one half of one percent of the nation's 180,000 FFLs. $^{80}$ In one recent case,

75. Violent Crime Control and Law Enforcement Act of 1994, Pub. L. No. 103-322, § 110201, 108 Stat. 1796, 2010 (1994).

76. SHELEY \& WRIGHT, supra note 51 , at 6.

77. This calculation excludes those respondents who already owned a handgun and those who indicated that they would not need one. Callahan \& Rivara, supra note 50, at 3039.

78. SHELEY \& WRIGHT, supra note 51 , at 6.

79. Callahan \& Rivara, supra note 50 , at 3039.

80. Seven hundred ninety-three dealers accounted for $49 \%$ of all traces; each dealer had at least 25 traces. See GlenN PIERCE ET AL., U.S. DEP'T OF TREASURY, THE IDENTIFICATION OF PATTERNS 
federal law enforcement authorities traced more than 220 guns seized in association with criminal activity to one Maryland FFL who has been charged with, among other things, selling guns without conducting proper background checks. $^{81}$ Most of these guns were seized in Washington, D.C., and at least twenty guns from this dealer are said to have been used in a feud between two groups of Washington, D.C., teenagers that resulted in a number of shooting deaths. ${ }^{82}$ Though it is not clear how often juveniles get guns directly from such dealers, these bits of evidence suggest that certain FFLs may develop reputations as easy sources from whom juveniles can purchase guns without proper identification. Further, some FFLs may take their guns directly to the street for sale to anyone. ${ }^{83}$

More signficantly, juveniles may obtain guns from sources once removed from legitimate dealers. Sheley and Wright report that thirty-two percent of their juvenile inmate respondents and eighteen percent of their student respondents had asked someone to purchase a gun for them at various sorts of retail outlets. ${ }^{84}$ Also, as noted previously, substantial percentages of juveniles obtain guns from their family and friends. In many of these instances, the friend or family member may have been the original purchaser of the weapon. Without more systematic research, it is difficult to know how far these guns tend to be from the point of original purchase. Overall, it seems reasonable to conclude that a sizeable proportion of juveniles acquire firearms directly from licensed dealers or from sources only once removed from licensed dealers.

Even illegal gun-running operations do not appear to have particularly long distribution chains. Based on media accounts, a typical operation would appear to be one in which gun runners either purchase guns directly from legal outlets or recruit strawmen purchasers to procure the weapons. The gun runners then sell the guns on the street or sell them to particular groups (such as gangs or drug dealing operations) with which they do regular business. After this point, further circulation of the guns appears to be haphazard, as the guns get passed gradually among friends, family members, or associates, or are stolen.

Some operations may have even shorter distribution chains. In another example from Maryland, four dozen people were arrested in Spring 1994 for purchasing guns for minors and felons. ${ }^{85}$ The arrests were based on surveillance operations in which law enforcement agents watched for persons turning

IN FIREARMS TRAFFICKING: IMPLICATIONS FOR FOCUSED ENFORCEMENT STRATEGY, Table 5 (1995). Whether these are the largest dealers, whose per gun risk of a trace is hardly higher than for the massive number of small licensees, cannot be determined from the published data. Even if the risk per gun were the same, this observation suggests that it is sensible to target the relatively small number of FFLs producing large numbers of violations.

81. Philip P. Pan, Trail of Violence Keeps Leading to Md. Gun Shop, WASH. POST, Nov. 1, 1995, at $\mathrm{A} 1$.

82. Id.

83. O'Connor, supra note $37, \S 2$, at 3 .

84. SHELEY \& WRIGHT, supra note 51, at 6.

85. Jon Jeter, 4 Dozen Arrested in Md. Gun Sales to Minors, Felons, Wash. Post, May 12, 1994, at B1. 
guns over to other parties outside of gun stores. ${ }^{86}$ In a six-week period, law enforcement authorities had seized more than 200 weapons associated with this operation. ${ }^{87}$ Thus, even more formally organized gun traffic operations may involve very short distribution chains in contrast to illegal drug operations.

Sheley and Wright, having surveyed both juvenile correctional populations and high-risk schools, conclude that "it is obvious that there is a large informal street market in guns." ${ }^{" 88}$ For both their student and juvenile inmate samples, friends were frequent sources of guns, both actually and prospectively. ${ }^{89}$ For the students, family members were also a significant source; that was not true for the inmates, perhaps reflecting their weaker family contacts and the greater suspicion on the part of their families. As might be expected, inmates were more likely to have purchased their most recent gun on the street. The inmate sample included "[f]orty-five percent [who] could be described as gun dealers in that they had bought, sold, or traded a lot of guns." ${ }^{90}$ Three quarters of that group were occasional dealers; only one quarter was described as "systematic." 91 The cost of handguns was less than $\$ 100$ for three-quarters of those students who owned one. ${ }^{92}$ Forty-one percent of students (and seventy percent of inmates) thought it "no trouble at all" to obtain a gun. ${ }^{93}$ Guns do indeed seem cheap and accessible to inner-city youth, without direct recourse to the primary market. They are accessible without the operation of large distribution systems that create large inventories of illegal weapons.

\section{E. Link to Drug Markets}

As already noted, drug dealers and drug addicts appear to be very active in selling guns. Forty-three percent of Sheley and Wright's juvenile inmate respondents stated that all or most of the drug dealers they knew also dealt in guns, and six percent of the respondents who had dealt guns indicated having bought guns from drug dealers. ${ }^{94}$ More generally, thirty-six percent of the inmates and twenty-two percent of the students cited drug dealers as a likely source from which they could obtain guns. ${ }^{95}$ Among handgun owners, on the other hand, only nine percent of the inmates and two percent of the students

86. Id.

87. Id.

88. SHELEY \& WRIGHT, supra note 51 , at 7.

89. Id. at 6

90. Id. at $7-8$ (emphasis in original).

91. Id. at 8 .

92. Id. at 7 .

93. The student figure is higher than the percentage of high school seniors nationally reporting that cocaine is "available or readily available" but lower than for marijuana. See INSTITUTE FOR SOCIAL RESEARCH, supra note 6 . The comparison is only a rough one since both the questions and the sample are different.

94. SHELEY \& WRIGHT, supra note 51 , at 9.

95. Id. at 6 . 
stated that they had actually obtained their most recent handgun from a drug dealer. $^{96}$

Drug addicts appear to provide many guns to the illegal market, often through theft. Desperate crack addicts have been reported to sell guns for as little as ten dollars in some cities. ${ }^{97}$ In addition, crack addicts may be recruited as straw purchasers for gun traffickers. ${ }^{98}$ Among Sheley and Wright's juvenile inmate and student respondents, the majority who described themselves as gun dealers cited acquisitions from drug addicts as one of their most common sources of guns. ${ }^{99}$ Thirty-five percent of the inmates and twenty-two percent of the students identified drug addicts as a likely source from which they could obtain a firearm, and among those actually owning a handgun, twelve percent of the inmates and six percent of the students said their most recent handgun acquistion had been from a drug addict. ${ }^{100}$

This information suggests that drug dealers and drug addicts are major participants in illegal street transactions involving guns and juveniles. We noted earlier that forty-three percent of Sheley and Wright's juvenile inmate respondents and twenty-two percent of their student respondents indicated that their most recent handgun acquisition had been from what one might consider street sources (that is, a drug dealer, a drug addict, or another street seller).$^{101}$ For inmates, twenty-one percent of their purchases, or approximately forty-nine percent of their street acquisitions, came from drug dealers or addicts. ${ }^{102}$ For students, eight percent of their acquisitions came from drug dealers or drug addicts, amounting to about thirty-six percent of their street acquisitions. ${ }^{103}$

\section{F. Other Factors}

Guns are very bulky compared to drugs. An individual can carry a modest number on his person, but in many circumstances, particularly in hot weather, it will be hard to do so inconspicuously. The possibility of detection constrains the operation of street markets very substantially; inventory has to be maintained in an interior setting or the seller takes very great risks. Of course, the transaction need not occur at the point of contact between buyer and seller. In this respect, retail gun purchases are more like wholesale than retail drug deals; meetings occur in accessible settings primarily for the purpose of arranging the transaction in a more protected location. Such markets are not impenetrable, but the lack of inventory at the point of the transaction certainly

96. Id.

97. Walsh, supra note 46 , at A14.

98. Thomas, supra note 37 , at A1.

99. SHELEY \& WRIGHT, supra note 51 , at 8.

100. Id. at 6.

101. Id.

102. Id.

103. Id. 
complicates policing, as compared to drug enforcement, where the existence of inventory at the purchase point is often a principal source of evidence.

As with drug retailing, entry into the gun supply business requires neither significant capital nor skill. A drug or gun seller may simply be a user who has either accumulated enough money to buy at the very low bulk level (ten bags of heroin, three guns) or has found a current retailer willing to provide revolving credit. It does require a modest level of prudence for continued success but no specific technical skill.

IV

\section{CONCLUSION}

\section{A. Generally}

The prior analysis of market characteristics suggests that illicit gun markets serving urban youth are likely to provide quite poor targets for intensified enforcement. The principal reasons for this are the infrequency of purchase, the intimacy of sellers and buyers, lack of a lengthy distribution chain, and ease of entry into the market. Only the high criminality of drug market sellers, who may be an important source for at least some youths, offers a basis for optimism. Empirical evidence will, of course, trump this deductive reasoning, but, as of yet, there is little available. Lawrence Sherman's experiments in intensified patrol activities targeting gun-carrying fall into a different category; they do not target the market but simply a distantly related behavior. ${ }^{104}$

Table 1 provides our assessment of the various factors affecting the susceptibility to policing of two drug markets and the youth market for illicit guns. The entries are highly judgmental; we have left one entry as a question mark and might have more prudently done so for others. Not every factor in the table is discussed in the text.

104. LaWrence W. Sherman et al., Nat'l Inst. of Justice, The Kansas City Gun EXPERIMENT (1995). On the apparent effectiveness of aggressive searches of minor order violators in deterring gun carrying, see Clifford Krauss, New York's Violent Crime Rate Drops to Lows of Early 1970 's, N.Y. TIMES, Dec. 31, 1995, at A1. 
TABLE 1

FACTORS AFFECTING THE SUSCEPTIBILITY OF ILLICIT MARKETS to EFFective Policing

\begin{tabular}{|c|c|c|c|}
\hline $\begin{array}{l}\text { Density of } \\
\text { Customers }\end{array}$ & $\frac{\text { Heroin }}{\text { High }}$ & $\frac{\text { Marijuana }}{\text { Medium }}$ & $\frac{\text { Youth Guns }}{\text { Medium }}$ \\
\hline $\begin{array}{l}\text { Closeness of } \\
\text { customers and } \\
\text { sellers }\end{array}$ & High & Medium & Medium-High \\
\hline $\begin{array}{l}\text { Customer } \\
\text { criminality }\end{array}$ & High & Low & Medium-High \\
\hline $\begin{array}{l}\text { Customer } \\
\text { poverty }\end{array}$ & High & Low & Medium \\
\hline $\begin{array}{l}\text { Transaction } \\
\text { frequency }\end{array}$ & High & Medium & Low \\
\hline $\begin{array}{l}\text { Urgency/ } \\
\text { impulsivity }\end{array}$ & High & Medium & $?$ \\
\hline $\begin{array}{l}\text { Distribution } \\
\text { chain length }\end{array}$ & High & Medium & Low \\
\hline Bulkiness & Low & Medium & High \\
\hline $\begin{array}{l}\text { Barriers } \\
\text { to entry }\end{array}$ & Low & Low & Low \\
\hline $\begin{array}{l}\text { Price relative } \\
\text { to legal market }\end{array}$ & High & Medium & Low \\
\hline
\end{tabular}

Guns are purchased infrequently by youth; most purchasers probably do so less than once per annum, very few as often as quarterly. Even if one focuses on high-rate offenders (and our interest in gun markets is largely instrumental, a device for reducing certain kinds of offenses), the frequency probably remains very low, surely no more than monthly. Not surprisingly then, there seems to be no gun counterpart to the street markets in which cocaine and heroin are sold.

A non-trivial fraction of guns are nonetheless sold in stranger-to-stranger transactions, reflecting the low levels of intervention of police agencies 
(including state and federal agencies such as the Bureau of Alcohol, Tobacco, and Firearms). Would the loss of such sales in a high intervention environment have much impact on youths' use of guns? The fact that high-risk users have numerous friends and acquaintances who are themselves potential sources, either as users willing to sell from their current inventory or as small scale regular sellers, suggests that it would not. We noted earlier that street sources seem to be more important for juvenile offenders than for youths in general. Hence, disruption of street sources could have its greatest impact on those juveniles who pose the greatest risk. But available evidence suggests that around eighty percent of juvenile offenders can obtain weapons from friends or relatives if necessary. ${ }^{105}$

The supply of new guns into this market is not the result of specialized production or distribution but comes primarily from non-specialized theft and illegal transfers, which produce a regular flow of guns into local markets. ${ }^{106}$ Given the low risk of apprehension for any single theft, increasing the penalty for possession of a stolen weapon does not seem likely to have a large impact on the flow from theft.

Urgency and impulsivity are difficult to assess. An insulted youth without a handgun may see himself in urgent need of such a weapon for revenge. Yet, the urgency is unpredictable (hence impulsivity). Although these transactions may be high risk, they may be a small share of all transactions. If delaying the acquisition of a gun lowers the probability of lethal conflict, because passions quickly cool, then efforts to complicate purchase (for example, by eliminating specific locations where guns are known to be readily available) may produce noticeable reductions in gun-related mortality, even if prices and perceived availability are not deeply affected. However, the very small number of transactions suggests that the market for these high-risk transactions will work very poorly. Efficient markets require some degree of continuity in time; otherwise the sellers will require very large compensation for down time between customers and the price charged impulse buyers will be high enough that the market may never form. Friends and drug markets may be strongly preferred when the need for a gun is urgent.

Dealer impulsivity is also relevant. One link between gun and drug markets is that some drug users will sell their guns in order to finance drug purchases. Under these circumstances, the seller is not likely to be cautious; locationspecific markets may develop in which gun buyers know that a purchase may be made rapidly from urgent sellers who will discount their guns below usual prices. ${ }^{107}$ These markets may be vulnerable to enforcement.

105. SHELEY \& WRIGHT, supra note 51, at 6.

106. All the research data reported here come from an era when intra-family transfers were legal, before passage of the 1994 Gun Control Act that required prior written parental consent.

107. In Amsterdam, a parallel phenomenon has been observed for prostitution. Male customers will wait around drug selling locations until they find a female heroin addict desperate enough to agree to sex for a price below the customary level. (Personal communication from ethnographer in Amsterdam, 
The gun market seems most closely to resemble that for marijuana among retail drug markets. Both commodities are usually sold in transactions among acquaintances; stranger-to-stranger transactions constitute a modest share of the market. Correspondingly, street markets are of only minor importance in the aggregate, though potentially more so for particular groups. Transactions are infrequent. The home-production possibilities for marijuana, not much used, have their counterpart in the potential for gun buyers to obtain their own guns through theft. In addition, marijuana users buy large enough quantities that they probably are willing to provide small amounts to friends who have temporarily run out.

\section{B. Strategic Issues and Areas for Experimentation and Research}

This article is generally pessimistic about strategies aimed at suppressing the supply-side of the illicit gun market. We have not assessed strategies targeting primary market control efforts, aimed at reducing the availability of guns to urban youth, or demand-side programs. ${ }^{108}$ There may indeed be some policing strategies aimed at illicit transactions away from licensed gun dealers that could significantly affect gun availability, particularly handgun availability, for youth, but they are hard to identify. In the absence of much experience with such enforcement, it seems sensible to reflect on the characteristics of markets that will determine the impact of tougher enforcement. At a minimum, this would help with the design of experiments.

Clearly, there is also a need to learn more about the dynamics of informal gun markets. Philip Cook has suggested that prices show not only sensitivity to primary market regulation, but also that there is great price dispersion, with poorly informed and impulsive buyers and sellers being a significant share of the market. ${ }^{109}$ Systematic data on gun prices by location and time would be a useful starting point for many analyses. One problem in gathering such data is the great variety of guns; the market is apparently not dominated over the longrun by a few specific models, so that price data will have to be collected for a number of different guns and the relevant mix changes over time. It would also be useful to do some "search time" studies, as Ann Marie Rocheleau and David Boyum have recently done for heroin, ${ }^{110}$ to determine just how difficult it is for various classes of buyers to obtain guns and how that difficulty is affected by different enforcement tactics.

The most promising control strategies may well be away from the gun market itself. Thus, geographically focused enforcement tactics, such as direct surveillance, sweeps, and buy-and-bust operations, are likely to be most effective

1991).

108. This is also a conclusion reached by SHELEY \& WRIGHT, IN THE LINE OF FIRE: YOUTH, GUNS AND VIOLENCE IN URBAN AMERICA 153-54 (1995).

109. Cook et al., supra note 45 , at 71 .

110. ann Marie Rocheleau \& David Boyum, Office Of Nat'l Drug Control Pol'y, MEASURING Heroin AVAILABILITY IN THREe CITIES (1994). 
if they are directed at locations where drugs are sold. Similarly, police could place greater emphasis on obtaining information regarding the sources of guns seized during narcotics raids. Operations directed at schools may also lead authorities to important players in the youth gun market, though such operations can raise controversy. As we mentioned previously, surveillance directed at particular gun shops has also led to important arrests. These tactics have the potential to reduce supply from sources that appear to be more important to the most dangerous juvenile offenders. Nevertheless, the factors discussed previously suggest that these tactics may not have much effect on the overall market. Systematic evaluation of demonstration projects is probably the right level of policy innovation at present.

The same can be said about encouraging law enforcement agencies to place greater emphasis on getting information from juvenile gun offenders regarding their gun sources. Such backward tracing may reveal that there is more concentration among juvenile gun sources than is apparent from available information; the many high school youths who report that they can get guns from friends or acquaintances may be thinking of a small set of friends and acquaintances whom they have in common. Considering the difficulties with geographic, observational tactics, a search for concentration of gun sources among people, groups, or businesses might hold more promise than is apparent from available information. Hence, it may prove more productive to emphasize the points of origin of the guns rather than the points of transfer.

Philip Cook and James Leitzel suggest that productive enforcement measures against the informal gun market would involve targeting undocumented sales by scofflaw FFLs, sales by FFLs to strawman purchasers, and increasing incentives of gun owners to secure their firearms so as to reduce thefts of guns from homes and businesses. ${ }^{111}$ Based on our analysis, such strategies seem to hold more promise than typical drug enforcement strategies, a point also noted by Cook and Leitzel. ${ }^{112}$ For instance, more systematic tracing of firearms seized from youths might lead to the identification of scofflaw FFLs who are the original sources of a disproportionate share of firearms used in crime. Earlier, we noted that more than half of the firearms submitted by police to the Bureau of Alcohol, Tobacco, and Firearms for tracing are traced to less than one-half of one percent of all FFLs. ${ }^{113}$ Identifying and prosecuting such dealers may cut off much of the youth gun supply. At this point, however, we do not know what percentage of the juvenile gun supply originates from scofflaw dealers. The same is true for strawman purchases and thefts.

Furthermore, scofflaw dealers and strawman purchases can be targeted by strategies aimed at the formal market. We have not endeavored to analyze legal market strategies in this article, but we can speculate that these sources of

111. Philip J. Cook \& James A. Leitzel, "Perversity, Futility, and Jeopardy": An Economic Analysis of the Attack on Gun Control, 59 LAW \& CONTEMP. PROBS. 91, 114-15 (Winter 1996).

112. Id. at 113-14.

113. PIERCE ET AL., supra note 80 , at tbl. 5 . 
illicit guns might be pursued more productively through restrictions on the primary gun market. For example, the federal government's recent steps to strengthen the applicant screening process for federal firearm licenses and raise fees on licensees may reduce the number of scofflaw dealers. Restrictions on the number of handguns one can buy within a particular period of time (such as the one handgun purchase per month laws enacted in South Carolina and Virginia) should make strawman purchases more difficult, though such measures should be weighed against their costs on law-abiding gun purchasers and against the possibility that they could lead to an increase in the illicit market for long guns and/or changes in patterns of interstate handgun trafficking.

A benefit of suppressing open-air drug markets is the disruption of a small but high-damage niche of the system by which youths obtain handguns. Aggressive enforcement of laws prohibiting concealed weapons may reduce the willingness to bring guns to locations for transactions. Sweeps of public housing, aimed at removing the stock of guns, may have an impact for some period of time. To say that market enforcement is unpromising is not to doubt that there are other modes for keeping guns from youths.

Finally, we note that guns are by no means ubiquitous among youths or in the commission of crimes. ${ }^{114}$ Might this be attributed to the effectiveness of our current control systems and hence imply that our pessimism is overstated? First, it is important to note that most crimes, particularly those committed by juveniles, are impulsive, opportunistic, unplanned activities. ${ }^{115}$ In order to commit a gun crime, a youth must either have the gun in his possession at the time a criminal opportunity arises, or he must plan ahead so that he will have the gun when it is needed. Though many juveniles can get guns if they know they will need them, the majority do not own them or carry them on a regular basis due to the factors discussed above. In terms of gun carrying, only twelve percent of Sheley and Wright's inner-city student respondents reported carrying a gun most or all of the time. ${ }^{116}$ Another twenty-three percent reported carrying a gun occasionally. ${ }^{117}$ Survey work among older male adolescents in Rochester, New York indicates that about one-quarter of self-reported gang members and only four percent of non-gang members report having carried a gun within the last six months. ${ }^{118}$ Thus, it is not surprising that most juvenile crimes are committed without firearms.

The question is how much of this is attributable to enforcement against the secondary, illicit market. The regulations on the primary market (that is, the

114. According to figures from the National Crime Victimization Survey, approximately one-third of aggravated assaults and one-quarter of robberies are committed with guns. MARIANNE ZAWrTZ, HIGHLIGHTS FROM 20 YEARS OF SURVEYING CRIME VICTIMS: THE NATIONAL CRIME VICTIMIZATION SURVEY, 1973-92, at 29 (1993).

115. Michael R. GotTfredson \& Travis Hirschi, A General THEORY OF CRIME $91-92$ (1990).

116. SHELEY \& WRIGHT, supra note 51 , at 5 .

117. Id.

118. Beth Bjerregaard \& Alan J. Lizotte, Gun Ownership and Gang Membership, 86 J. CRIM. L. \& CRIMINOLOGY 37, 47 (1995). 
prohibition of sales to juveniles), as well as the prices of guns, limit juvenile gun ownership. Further, the risks associated with carrying a gun might deter some juvenile gun owners from carrying their firearms on a regular basis. A second factor may be a general aversion to guns held by many persons. Without claiming that enforcement against the illicit market is "futile" in terms of the Hirshman framework introduced by Cook and Leitzel, we do argue that the experience with illicit drugs suggests that illegal market enforcement is likely to have a modest role. 


\section{APPENDIX \\ Estimating THE NUMBER OF GUN TRANSACTIONS}

\section{A. Numbers of Guns Owned by Gun Owners.}

Available studies do not always clarify the number of guns owned by respondents. One exception is a study by Alan Lizotte involving youths in Rochester. ${ }^{\mathrm{Al}}$ Overall, the sixty-seven male respondents possessing guns reported owning a total of ninety-two guns, for an average of 1.37 guns per owner. $^{\mathrm{A} 2}$ Those youths owning guns for protection owned an average of 1.67 guns. ${ }^{\mathrm{A} 3}$

A higher estimate can be derived from Sheley and Wright's survey of male juveniles in several cities. The calculations below exclude the juvenile inmates and use only the inner-city student respondents. Seven hundred twenty-eight students answered questions about the specific types of guns they owned (two questions were answered by only 727 students). ${ }^{4}$ For each type of gun, Sheley and Wright provide the percentage of students who reported owning that type of gun at the time of the survey. ${ }^{\mathrm{AS}}$ The categories appear to be mutually exclusive; thus, one can multiply the number of respondents by the percentage owning the type of weapon to estimate how many weapons were owned by the respondents. (The calculations exclude homemade guns.)

The figures were as follows: (1) target or hunting riffe [eight percent]; (2) military-style semiautomatic or automatic rifle [six percent]; (3) regular shotgun [ten percent]; (4) sawed-off shotgun [nine percent]; (5) revolver [fifteen percent]; (6) automatic or semiautomatic handgun [eighteen percent]; (7) derringer or single shot handgun [four percent] ${ }^{\mathrm{A} 6}$

Adding these numbers indicates that the 728 student respondents owned approximately 510 guns. This calculation assumes that the respondents owning each type of gun possessed only one such gun. This may not be a safe assumption. On the other hand, some of the respondents indicating ownership of a gun may actually have shared ownership with someone else, and some may have exaggerated their gun ownership. For the purposes of arriving at an

A1. Alan J. Lizotte et al., Patterns of Adolescent Firearms Ownership and Use, 11 JUST. Q. 51 (1994).

A2. Id at 62 .

A3. Id.

A4. JOSEPH F. SHELEY \& JAMES D. WRIGHT, JR., NAT'L INST. OF JUSTICE, GUN ACQUISITION AND POSSESSION IN SELECTED JUVENILE SAMPLES 4 (1993).

A5. Id.

A6. Id. 
approximate figure, perhaps we can assume that the respective factors overstating and understating ownership cancel one another.

Interestingly, this averages out to almost one gun per respondent $(510 / 728$ $=0.7$ ). However, only twenty-two percent of the students actually indicated ownership of a gun. ${ }^{A 7}$ If we assume that the ownership rate was twenty-two percent among the 728 respondents to the questions concerning gun type, then we have 160 gun owners for an average of $510 / 160=3$ guns per gun owner. Though we do not know how many guns the respondents had ever owned or how many gun transactions they had ever made, it seems the best we can do is to estimate three gun transactions (that is, acquisitions) per owner.

This estimate of guns owned is consistent with Sheley and Wright's Table 1, which indicates that twenty-two percent of the students owned guns and that fifteen percent owned three or more guns. ${ }^{A 8}$ Thus, more than two thirds of the gun owners owned three or more guns. ${ }^{\mathrm{A} 9}$

\section{B. Applying the Estimates to Washington, D.C.}

Based on the Sheley and Wright data, we can tentatively estimate that twenty-two percent of inner-city high school males own guns, and that these gun owners have an average of three guns. Our first calculation below focuses on legal juveniles in the high school age range of thirteen to seventeen years. We then expand the calculation to include eighteen- to twenty-year-olds. ${ }^{\mathrm{A} 10}$

Applying these figures to Washington, D.C., there were 14,981 males aged thirteen to seventeen in that city in $1990 .{ }^{\mathrm{A} 11}$ We can estimate that twenty-two percent, or 3,296, of these youths owned guns. If, on average, each of these teens owned three guns, then overall they possessed $3,296 \times 3=9,888$ guns. Conversely, they had engaged in 9,888 gun acquisitions over their gun-owning lifetimes. Based on figures reviewed previously, about twenty to twenty-five percent of juveniles get their guns from street sources such as drug dealers, drug addicts, or other street sellers. The exact figure for Sheley and Wright's students is twenty-two percent. ${ }^{\mathrm{A} 12}$ Applying this figure, one can estimate that $9,888 \times .22=2,175$ of the gun acquistions by these youths came from street sources.

Estimating a time frame for these transactions is difficult. Sheley and Wright did not ascertain the age of first gun acquisition for their respondents. In general, juvenile gun studies reveal little about this point. Yet, even if we assume that all of these transactions took place in one year (that is, each of the juvenile gun owners acquired all of his guns in one year), we are left with only

A7. Id. This figure is based on 741 respondents.

A8. Id.

A9. Id

A10. The average age of Sheley and Wright's respondents was 16 , with $19 \%$ over the age of 17 .

A11. U.S. BuREAU OF THE CENSUS, 1990 CENSUS OF THE POPUlation: GENERAL POPUlation CHARACTERISTICS 14 (1992) (population figures for Washington, D.C.).

A12. SHELEY \& WRIGHT, supra note A4, at 6. 
$2,175 / 365=6$ gun acquisitions per day from street sources by inner-city males in the high school age range. If we expanded this to include eighteen- to twenty-year-olds, we would add a further 16,592 youths. The new per day figure would be thirteen.

As a caveat to these calculations, we note that due to the general ban on handgun ownership in Washington, D.C., youths in that city may find it necessary to acquire firearms from street sources more often than do youths in other cities, potentially biasing our estimates downward. Nevertheless, the purpose of our calculations is to illustrate what the available figures on juvenile gun acquisition imply with respect to the numbers of street transactions made by juveniles and young adults in a major metropolitan area. 